\title{
Women's Perceptions of Pain and Discomfort after Childbirth in Angola
}

\author{
Elisabeth Jangsten ${ }^{1,2}$, Roland Strand', Engrácia da Glória Gomez de Freitas', Anna-Lena Hellström², Annika \\ Johansson ${ }^{3}$ and Staffan Bergström ${ }^{3}$
}

\begin{abstract}
Prophylactic treatment against postpartum haemorrhage is a widely investigated area and injection of Oxytocics has been considered as the best choice. The occurrence of postpartum pain and discomfort was studied in a population of birthing women in an overcrowded labour ward in Angola where the oxytocin-filled device Uniject ${ }^{\mathrm{TM}}$ was used. This study indicates that birthing women's perceived postpartum pain increases with parity and during breastfeeding, but does not confirm that injection of oxytocin increases pain and discomfort. This is an important finding, since it might facilitate the introduction of a management practice, likely to reduce haemorrhage-related maternal morbidity and mortality after delivery in underprivileged populations. The birthing women were, by and large, satisfied with the care and treatment provided, but the encounters with midwives seem to vary in quality. Further investigation is needed to elucidate parturient women's experience of postpartum pain and their perceptions of the quality of care and treatment. (Afr J Reprod Health 2005; 9[3]:148-158)
\end{abstract}

\section{RÉSUMÉ}

La perception de la douleur et la gêne chez les femmes après l'accouchement en Angola. Le traitement prophylactique contre l'hémorragie est un domaine qui a été bien étudié et l'injection des oxytoxiques est considérée comme la meilleure option. La survenue de la douleur et de la gêne postpartum à été étudiée chez une population de femmes en train d'accoucher dans une sale d'accouchement en Angola où un instrument plein d'oxytocine, UnijectTM, a été utilisé. L'étude montre que la douleur postpartum perçue chez les femmes en train d'accoucher augmente avec la parité et pendant l'allaitement, mais ne confirme pas que l'injection de l'oxytocine augmente la douleur et la gêne. Ce résultat est important puisqu'il peut faciliter l'introduction d'une pratique de suivi qui probablement réduira la mortalité et la morbidité maternelles liées à l'hémorragie après l'accouchement auprès des populations démunies. Les femmes en train d'accoucher étaient plus ou moins satisfaites des soins et des traitements offerts, mais leurs expériences auprè des sages-femmes semblaient varier en qualité. Il faut advantage études pour élucider l'expérience de la douleur postpartum chez les femmes parturientes ainsi que leur perceptions de la qualité de soin et de traitement. (Rev Afr Santé Reprod 2005; 9[3]:148-158)

KEY WORDs: Postpartum haemorrbage, third stage of labour, labour pain, satisfaction with care

${ }^{1}$ Department of Obstetrics and Gynaecology, Sablgrenske University Hospital, Gothenburg, Sweden. ${ }^{2}$ Institute of Nursing, The Sablgrenska Academy at Göteborg University, Gothenburg, Sweden. ${ }^{3}$ Division of International Health (IHCAR), Department of Public Health Sciences, Karolinska Institutet, Stockholm, Sweden. ${ }^{4}$ Curso de Espezializacão de Parterias, Ministerio de Saúde, Luanda, Angola

Correspondence: Elisabeth Jangsten E-mail: elisabeth.jangsten@vgregion.

\section{Introduction}


Among complications during pregnancy and childbirth, postpartum haemorrhage (PPH) is the single most important cause of maternal mortality ${ }^{1}$. $\mathrm{PPH}$ is defined as 'blood loss of ${ }^{3} 500 \mathrm{ml}$ during the first 24 hours postpartum'. This level is arbitrary and for some women even less can be life threatening, particularly among those who suffer from severe anaemia. The prevalence of PPH is between 10 and 20\% of all deliveries and the most common cause is uterine atony ${ }^{2,3}$. Several studies have shown that active management during the third stage of labour, AML, especially administration of uterotonic drugs, reduces the incidence of PPH by up to $40 \%{ }^{1,4,5}$. The steps in AML are in the following order:

(1) early cord clamping,

(2) injection of oxytocin,

(3) traction of the umbilical cord during expulsion of the placenta ${ }^{6}$.

WHO recommends that AML should be actively promoted in low-income countries where anaemia is widespread and treatment of blood loss may imply significant problems ${ }^{7}$. However, some women complain about oxytocin-induced postpartum pain, so-called "after pains".

Hitherto there have been no studies on the acceptability of oxytocin injection for birthing women, or of the degree of pain caused by the injection as perceived by the women. The International Association for the Study of Pain defines pain as "an individual sensorial and emotional experience correlated with actual or potential tissue damage, or describes it in terms of damage" .

The word "pain" is from the Latin "poena", which means "punishment". Labour pain has always been considered a normal phenomenon, though a unique pain experience, because it is intense and expected. Many women describe it as the most severe pain they have experienced. Pain during this circumstance is an important signal indicating that labour has started and the perception of pain increases as labour progresses ${ }^{8}$.

Several variables correlate with labour pain. The major determinant of labour pain is parity, primiparous women having more pain than multiparous women ${ }^{\text {? }}$.

One of the most important tasks for a midwife, except providing obstetric care, is to support women during pregnancy and childbirth. It has been demonstrated that empathetic and physical support during labour has many benefits, including shorter labour and less medication. It also reduces anxiety and helps mothers to cope with labour pain and thus improves the childbirth experience ${ }^{6}$.

The literature describes different methods to assess labour pain. The visual analogue scale (VAS) is the most frequently used self-assessment scale of pain intensity. It is a plastic instrument that can easily be held in the hand, utilising a line from zero to ten with a moveable marker, where zero means no pain and ten means intolerable pain. The woman assesses her pain and puts the mark on the line $e^{8}$.

Another method is the McGill Pain Questionnaire, which is a long list of words intended to describe the pain, and implies a multidimensional assessment ${ }^{9}$. It provides three types of measurements: pain-rating index, number of words chosen to express pain, and assessment of pain intensity.

The Pain-O-Meter, POM, is partly based on a simplified version of the McGill Pain Questionnaire and VAS developed for clinical use ${ }^{10}$. On one side there are descriptive words (e.g., cutting, burning, aching, fearful, torturing, and horrible). Each word has a ranking value unknown to the patient. The Pain-O-Meter provides an assessment of the sensory and affective dimensions of pain experience.

The verbal rating scale, VRS, is another selfassessment scale, including 3 to 5 expressions such as weak, medium or strong. The advantage of these scales is that they are easy to use and give immediate information ${ }^{8}$. 
150

African Journal of Reproductive Health

While pain during the first and second stage of labour is given extensive scientific attention, ${ }^{8,9,11}$ this is not the case for postpartum pain. This was demonstrated in a study in England of 100 primiparous and 100 multiparous women, who were interviewed after 48 hours. Fifty of the primiparous and 86 of the multiparous women complained of lower abdominal pain during the third stage of labour ${ }^{12}$. The study did not explore what kind of management was used during the third stage of labour.

Angola has been ravaged by a civil war for more than 40 years, causing extreme hardship for the population. Less than one-third of the population has access to health services and one of three children dies before the age of five. Life expectancy is 42 years and $70 \%$ of the women are illiterate. The institutional maternal mortality ratio, MMR, in 2003 in the national capital, Luanda, was 1,320 per 100,000 live births. Postpartum haemorrhage is one of the main causes of death, making it important to reduce critical blood loss during the third stage of labour ${ }^{13}$.

Uniject $^{\mathrm{TM}}$ is a disposable injection device consisting of a pre-filled, plastic tube with $10 \mathrm{IU}$ of oxytocin and a sterile needle attached for intramuscular injection. It has been tested in thirdstage labour in Indonesia, where midwives preferred it to the standard use of needles and syringes ${ }^{14}$. In 1999 WHO initiated the Uniject $^{\mathrm{TM}}$ project at Maternidade Lucrécia Paím (MLP) in Luanda, in collaboration with the Division of International Health (IHCAR) Karolinska Institutet in Stockholm. The Uniject ${ }^{\mathrm{TM}}$ project studied the postpartum blood loss before and after introduction of AML with Uniject ${ }^{\mathrm{TM}}$ and a drastic reduction of blood loss was demonstrated after the introduction of this $\operatorname{method}^{15}$.

The purpose of this study was to investigate the perceptions of pain and discomfort among birthing women in Angola in connection with the use of Uniject ${ }^{\mathrm{TM}}$ given as a part of AML, compared to women not receiving the treatment.

\section{Materials and methods}

Of a total population of around 13 million in Angola, approximately one-third lives in Luanda. Health statistics are scarce and unreliable, but it is estimated that 100,000-125,000 deliveries occur per year in Luanda, assuming a crude birth rate of 40-50 per thousand ${ }^{13}$. Approximately 50\% of all births take place at maternity wards or peripheral birth clinics.

MLP is the largest maternity hospital in Luanda and is also a referral hospital. In 1998 nearly 100,000 women sought for care and treatment and 16,000-17,000 deliveries occur yearly. About $20 \%$ of maternal mortality at MLP is due to $\mathrm{PPH}^{13}$.

The obstetric care unit staff consists of four to five midwives per shift and during one day midwives may assist 40-50 deliveries. The wards are crowded and the number of beds are insufficient. A woman in labour often has to share a bed with another woman and there is almost no privacy. Family members are not permitted to support a woman during labour at the maternity unit. During visiting hours families are allowed to bring food to birthing women.

In case of an emergency, where blood transfusion is necessary, there is often insufficient blood available. Staff members have to call the family, which must then arrange a blood donor and buy the necessary equipment for blood transfusion.

For the Uniject ${ }^{\mathrm{TM}}$ project, 12 midwives and 4 doctors were trained and defined as the project staff. At the obstetric care unit birthing women were included in the study by the project staff when they arrived at the maternity in labour between 08 am - 02 pm. The high workload did not permit all women to be included in the project. Women not included were treated routinely, which means that no treatment was given during the third stage of labour. All women were transferred after two hours to the postnatal ward to stay for a period between 6 and 24

African Journal of Reproductive Health Vol. 9 No.3 December 2005 
hours and it was during this period that this study was carried out.

A semi-structured questionnaire was developed and translated into Portuguese. The verbal rating scale (VRS) was chosen as the best alternative in this study setting and a four-grade scale about pain was used to distinguish "no pain", "a little pain", "intense pain", and "intolerable pain". It also included questions about the localisation of pain, breastfeeding, satisfaction of care and empathy shown to the women by staff.

The questions about satisfaction with care and degree of empathy were divided into "good", "average", and "bad". The last question was open-ended and labelled "own comments". Information about age, gestation, parity, birth weight, time of birth and time of expulsion of the placenta was retrieved from the patients' records. The women's comments in the openended question are described in themes by quotations according to the contents ${ }^{16}$.

It was not possible for the women to fill in the questionnaire by themselves because of the significant proportion of illiterate women, some of whom did not understand Portuguese. One of the authors (EGGF), having both cultural and professional competence, served as an interviewer. She did not wear a uniform, she was unknown by the mothers and they were not dependent on her as a care provider. It was not possible to do the interviews within the same time after delivery for all of the women. Some women had given birth early in the morning and some had just recently arrived to the postnatal ward.

The sampling of parturients was carried out during two weeks at the post-natal ward. Women were included in Group A if they were treated with AML and Uniject ${ }^{\mathrm{TM}}$, or Group B if they were treated according to the routine at the obstetric care unit. The interviewer received information about whom she was going to interview when she arrived at the post-natal ward. She was not informed whether the parturients belonged to Group A or Group B. The interviews were performed in the afternoons 2-12 hours after the delivery and lasted for about 10 minutes per woman.

The data were analysed from the two groups of women expressing postpartum pain and compared by use of the chi-square test with Yates' correction $^{17}$.

Permission was obtained from the ethical committee at Karolinska Institute, Stockholm, Sweden and from the Agostinho Neto University, Luanda, Angola.

\section{Findings}

Informed verbal consent was received from all women who participated in the study.

One hundred and two women were included and interviewed, of whom 51 belonged to group

Table 1: Parity distribution among all 102 birthing women in Group A and Group B.

\begin{tabular}{lcccc}
\hline Groups Parity & Primiparous & Multiparous & Grand Multiparous & Total \\
\hline Groups A & 19 & 27 & 5 & 51 \\
Group B & 21 & 21 & 9 & 51 \\
\hline Total & 40 & 48 & 14 & 102 \\
\hline
\end{tabular}

Definitions of parity in the study:

Priiparous: having the first baby

Multiparous: having the second, third or fourth baby

Grand multiparous: having the fifth (or above( baby)

African Journal of Reproductive Health Vol. 9 No.3 December 2005 
152 African Journal of Reproductive Health

$A$ and 51 belonged to group B. In group B, there is one record with no data about parity. There are also data missing about intensity of pain for one woman and about breastfeeding for another, both in group A. The average age was 24 years in group $A$ and 23 years in group $B$. The parity distributions are presented in Table 1.

A majority of the birthing women had been visiting antenatal clinics. Twenty-nine of the women in group A had a calculated gestational age according to the first day of last menstrual period. In group B, there were 27 women who had a calculated gestational age. Among these women, there were five pre-term deliveries and three post-term deliveries in Group A, and in Group B there were four pre-term deliveries and three post-term deliveries.

None of the multiparous or grand multiparous women had a previous caesarean section or instrumental delivery. In Group A, there were 9 mothers $(18 \%)$ who had lost one child and 3 mothers had lost 2 children. In Group, B 8 mothers $(16 \%)$ had lost one child, 3 mothers who had lost 2 children, one mother had lost 3 children and one had lost 5 children.

Seventy-five percent of the birthing women in both groups arrived at the maternity unit with a dilatation of the cervix between 6 and $10 \mathrm{~cm}$ and they delivered between 5 minutes and 3 hours after being admitted. The mean birth weight in group A was 3,100 g and in group B 3,200g.

Expression of pain was assessed in two ways that tried to take into consideration the social and cultural dimensions of the women approached. The quantifying of pain is expressed in Figures 1 and 2 and examples of the individual pain expressions are presented in quotations.

Postpartum pain was experienced by $45 \%$ of the women in group $A$, of that percentage 10 women said that they felt intense or intolerable pain. In group B, $37 \%$ felt pain after delivery and 5 women classified the pain as intense or intolerable pain (Figure 1). However, a chi-square test did not confirm a significant difference between the two groups $(p=0.55)$.
Multiparous women experienced more postpartum pain than primiparous women, irrespective of whether they had received any treatment during third stage of labour. Among 40 primiparous women, only 6 experienced pain after delivery. Multiparous and grand multiparous women totalled 62 and among them 36 women experienced postpartum pain. The difference is statistically significant $(p=0.002)$.

The pain ranking value was also assessed higher among the multiparous and grand multiparous women. In both groups, there were 15 women who ranked the pain as intense or intolerable and only two of them were primiparous women.

The pain was mostly described by the parturients in both groups as localised in the lower abdomen (90\%). Other localisations of pain were also described, such as lower back pain, upper back pain and epigastric pain.

Multiparous women who belonged to group A explained their pain and discomfort with the following words:

"After the delivery, I was put on a bedpan
about an hour. After that I got pain in my
back".
"After the birth, I did not feel any pain but
3 bours later I felt a lot of pain, in the lower
abdomen"
"After the birth, the pain disappeared but
an hour after the pain started in the lower
abdomen"

The multiparous women from group B describe pain in these sentences:

\section{"After the birth, I felt no pain. An hour later the pain started in my lower abdomen. It still continues". \\ "After six hours, it hurts in the lower abdomen"}

An analysis was made to see if time and memory could be a factor influencing the

African Journal of Reproductive Health Vol. 9 No.3 December 2005 
women's answers regarding intensity of pain. Most women were interviewed in the post-natal ward 4 to 8 hours after delivery. Approximately $20 \%$ of the women were interviewed between 2 and 4 hours after delivery and 9\% were interviewed 8-12 hours after delivery.

Thus the timefactor is not likely to have influenced the results in any significant way.

We also found that breastfeeding mothers in both groups had similar degrees of postpartum pain (Figure 2). Altogether were 61 breastfeeding mothers and 40 mothers who had not breastfed their new-borns before the interview. Breastfeeding mothers had more pain after delivery than nonbreastfeeding mothers by the time they were interviewed. Twenty-two mothers in group A complained of pain and 14 of them had breastfed. In Group B, 18 mothers experienced pain and 14 of them had breastfed. Only one primiparous woman from each group experienced intense or intolerable pain during breastfeeding.

Comments from the birthing women indicate that breastfeeding exacerbates postpartum pain. The comments about breastfeeding and pain are all from multiparous and grand multiparous women:

"The midwives told me to breastfeed, but I could not manage because it was too painful".

"I feelpain in the lower abdomen when I breastfeed".

"Seven hours after the birth I had a lot of pain when I breastfed".

Most of the women (75\%) were satisfied with the care they received at the maternity ward. In both Groups A and B, 38 women expressed full satisfaction, while 10 women in Group A and 11 women in Group B was reasonable satisfied. Three women in Group A and two in Group B were not satisfied.

On the question about empathy the result was similar. Thirty-two women in both groups found that the care providers' empathy was good,
13 women in Group A and 12 in Group B had the opinion that it was reasonable. Six women in Group A and 7 in Group B thought that the care providers' empathy was poor.

The last question was an open question, labelled "own comments". More than half, 57 of 102 women made comments in response to this. The comments mostly concerned women's postpartum pain and their perceptions of care and treatment. The comments are divided into five themes according to the content and described by quotations. The following themes were discussed:

(1) pain and discomfort,

(2) breastfeeding,

(3) satisfaction with care,

(4) behaviour, and

(5) economy.

In Group A, 28 women gave their comments and in the Group B, 29 women did so. The comments were similar in both groups and included not only satisfaction, but also dissatisfaction with the care.

It also elucidated the encounter with care providers. One woman from Group A seemed to be satisfied with the treatment and expressed it in these words:

\section{"This is the second time I give birth here. I was well treated. I did not have haemorrhage and the baby is healthy".}

A woman from Group B seemed to be pleased with the treatment by the care provider. ("Attention" could mean that she felt supported):

"The treatment was good, I liked it a lot. The nurse at sixth floor gave me a lot of attention and she continued in the delivery room".

The next sentence describes that "good behaviour" is favourable and screaming is equated 
Figure 1: Women's self assessed pain intensity after birth in Group A and Group B

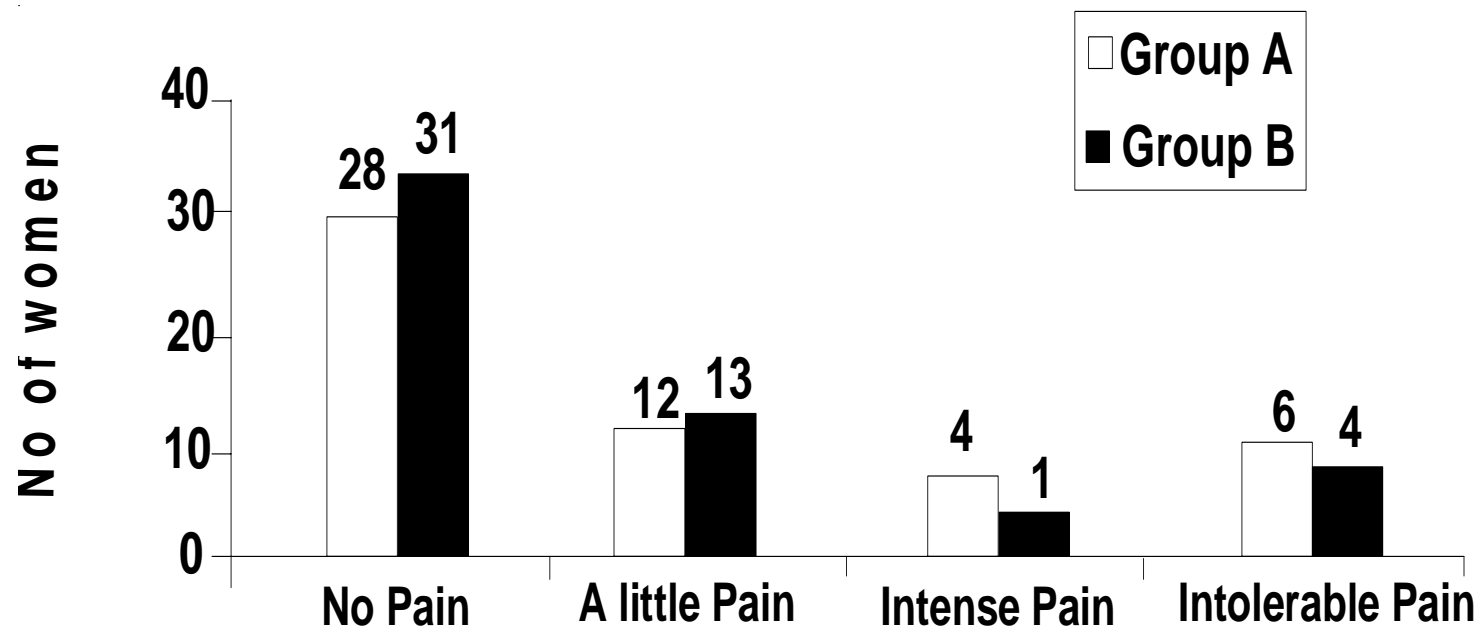

Figure 2: Women's perception of pain during breastfeeding

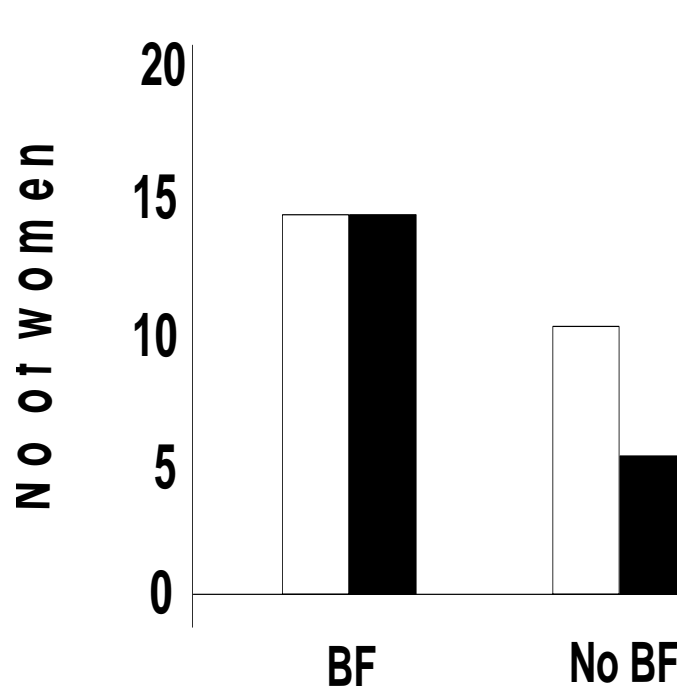

$\square$ Pain and Oxytocin
$\square$ Pain and No Oxytocin

$\mathrm{BF}=$ Breastfeeding before the interview

No. $B F=$ Not breastfeeding before the interview 
Women's Perceptions of Pain and Discomfort after Childbirth in Angola

with scandalous behaviour and is punished by the care providers, expressed in these words:

"I was well treated because I did not cause a scandal. The others who were shouting and crying were badly treated".

Several comments were about the behaviour of the health staff:

"I wish that the midwives who worked this morning always treated the patients like that. They did not scream and had no angry faces".

The following describes a perception of reasons for bad treatment from care providers:

'I was well treated because my sister-in-law is a midwife at this Institution. The other women who did not have their family, they were treated badly".

Some of the comments include advice to midwives about how to support and treat labouring women. One primiparous woman from Group A said:

"I hope midwives always are in a good mood at work and not nasty when it hurts a lot. Speak to them [the patients] always when it ispossible".

A grand multiparous woman said:

"When a mother had her baby she should not walk from the delivery room to the elevator with two nurses and six mothers. It is dangerous because she could be diray and fall with the baby".

Some of the comments indicate that economic conditions can play a role for the perception of care:

"When I arrived at 4 ' clock in the morning I was badly treated due to the fact I did not have money for gloves."

African Journal of Reproductive Health Vol. 9 No.3 December 2005
"When mothers are coming for having their babies, midwives should be occupied with the mother's pain instead of thinking of money."

\section{Discussion}

The principal finding in this study is that women receiving oxytocin in the third stage of labour by use of a disposable injection device did not report significantly more pain than women without administration of oxytocin. Hence, the introduction of AML, with the approach utilised, would presumably be acceptable in this population. Its advantages in terms of drastically reduced blood loss postpartum in the same population have already been demonstrated ${ }^{15}$ and it can be extrapolated that haemorrhagerelated maternal morbidity and mortality were significantly reduce by the introduction of AML in this population.

The results in our study showed that women's postpartum pain tends to increase with parity and may not always be correlated with the administration of oxytocin. We also found that breastfeeding tended to exacerbate postpartum pain and that increased postpartum pain can influence the mothers to avoid breastfeeding immediately after birth. A study in England demonstrated that perceived pain during breastfeeding increases with parity due to stronger contractions ${ }^{18}$.

Pain is a multidimensional experience with physiological, psychological and social components, and the pain of childbirth is rated as one of the most intense of all pains, but it is also extremely variable ${ }^{11}$. Birthing women's perception of pain and pain tolerance is influenced by various factors: the individual's previous experience, anxiety, cultural standards and education, etc. It was demonstrated in Israel that women with low educational levels, had higher ratings of pain during labour, assessed by a visual analogue scale (VAS), than highly educated women ${ }^{19}$. 
156 African Journal of Reproductive Health

It became obvious to the authors that both the simple recording of quantified pain and the qualitative approach utilised in the presentation of individual pain reactions are not easily translated in clear categories of responses. The social and cultural dimensions of the reality in which the studied women lived make interpretation of their reactions difficult. In the capital province of Luanda (still severely affected by the ongoing war at the time of the study), the extreme resource scarcity and the lack of security in combination with fear of and experience of rude staff behaviour certainly influenced both the perception and the expression of pain. Given all these negative circumstances, it appears that the introduction of yet another intervention (Uniject ${ }^{\mathrm{TM}}$ injection) might be expected to have aggravated the perception of pain still more. This did not appear to have been the case.

The accuracy of memory and recalling labour pain is widely discussed. The literature is relatively limited and many studies demonstrate methodological problems. It is shown that women do not completely forget labour pain and recall is often vivid, but not always entirely accurate ${ }^{11}$. In a study performed in Sweden, it was shown that the amount of pain and discomfort remembered was less than the amount of pain reported in labour by both primiparous and multiparous women ${ }^{20}$. Another study in Israel did not find differences between labour pains recorded immediately after delivery and recalled 2 days after ${ }^{21}$. Postpartum pain has not been a focus of investigations, probably because it is less severe than the pain in first and second stages of labour.

The method of Verbal Rating Scale (VRS) was considered appropriate when asking the mothers to assess their pain in this study setting. Studies about birthing women's postpartum pain had never been conducted before at the maternity unit used in the present study.

The results demonstrate that the mothers had pain by the time when they were interviewed, but not immediately after birth; this can be explained by the fact that they were happy and relieved when the delivery had been uneventful. We found that about $75 \%$ of the parturients in both groups were satisfied with the care and treatment they received and they were also pleased with the empathy shown by the midwives. This result might reflect that the women felt inhibited in expressing their opinions to an interviewer, instead of filling in a questionnaire on their own.

Surveys of patient satisfaction as a measure of health-care are important and should be used systematically; it can facilitate choice between alternatives in organising and providing healthcare ${ }^{22}$. Client satisfaction can be considered an integral component of perceived service quality. Support for this statement has been found in studies indicating that satisfied patients are more likely to continue using medical services. However, reliable information may not always be easy to collect and, for example, dependence on the provider may mute criticism of the service ${ }^{23}$.

The respondent's “own comments" enabled us to obtain opinions about the care received. It was obvious that this open question gave the women an opportunity to express their experiences and perceptions. Although the result of satisfaction and empathy gave positive assessment scores, many "own comments" gives another picture about care providers' treatment. These comments also offer insight for care providers and decision-makers.

There are studies that confirm the lack of communication between care providers and labouring women in overcrowded labour wards. During one study in Zambia, it was observed that communication during labour between the midwife and the labouring women was limited. The women were often left alone and had to call for the midwife when it was time to deliver ${ }^{24}$. In a study in Rakai district in Uganda, it was demonstrated that only $32 \%$ of the women chose public health units for delivery. Midwives 
were described as rude, proud, negligent and vulgar. They often tell mothers in labour demeaning words like "Do not disturb us!", "Who told you to become pregnant?" ${ }^{25}$.

In the perception of a positive delivery, the birthing women's encounter with the midwife plays a crucial role. In a Swedish study, women explained that being seen as individuals and receiving respect from the midwives gave them courage, and they did not have to be ashamed of their behaviour. They felt accepted and supported by the midwife, which gave them a positive experience and satisfaction ${ }^{26}$. Birthing women with good support are also likely to have more tolerance of pain and need less pain alleviation ${ }^{27}$.

In many low-income countries, the healthcare and staff's situation in labour wards is difficult because of work overload, low salaries and job dissatisfaction. It is important to be aware of the environment and the study setting. Scarcity of material, equipment and medicine is frustrating.

\section{Conclusion}

AML with administration of 10 IU of oxytocin did not significantly add to the burden of postpartum pain in the population studied. This is an important finding, since it might facilitate the introduction of a management proven to reduce haemorrhage-related maternal morbidity and mortality after delivery in this underprivileged population. Taking into account that many women experience a great deal of pain not only during labour, but also after delivery, further investigations are required with the aim of strengthening midwives 'consciousness of mothers' need for support and pain alleviation after delivery and during breastfeeding.

\section{Acknowledgements}

This study was made possible through financial support from the World Health Organization, Family and Reproductive Health, Geneva. We gratefully acknowledge the Management board at Maternidade Lucrécia Paím. The Angolan women are acknowledged for sharing their experiences and perceptions when giving birth at Maternidade Lucrécia Paím.

\section{REFERENCES}

1. McCormick M L, Sanghvi H C G, Kinzie B, McIntosh N. Preventing postpartum haemorrhage in low-resource settings. Int J Gynecol Obstet 2002; 77: 267-75.

2. WHO/MCH Safe Motherhood. The Prevention and Management of Postpartum Haemorrhage. Report from a technical working group, Geneva: 1989, 9.

3. Akins S. Postpartum hemorrhage. A 90s approach to an Age-Old problem. J Nurse Midwifery 1994; 39(2): 123-34.

4. Prendiville W, Elbourne D, Chalmers I. The effects of routine oxytocic administration in the management of the third stage of labour: an overview of the evidence from Controlled Trials. Br J Obst Gyn 1988; 95 : 3-1.

5. Nordström L, Fogelstam K. Routine Oxytocin in the Third Stage of Labour: A Placebo Controlled Randomised Trial. Br J Obst Gyn 1997;104: 781-86.

6. WHO/FRH/MSM- Care in Normal Birth: a practical guide. WHO / FRH / MSM / 96.24.

7. Enkin M, Keirse M J N C, Renfrew M, Neilson J. Third stage of labour. In: Enkin M (Ed). A Guide to: Effective Care in Pregnancy and Childbirth. 2nd ed. New York: Oxford University press, 1995, 236-42

8. Frid G. Labour pain.[Dissertation]. Gothenburg, Sweden: University of Gothenburg 1988. 35 pp.

9. Melzack R. Labour pain as a model of acute pain. Pain 1993; 53: 117-20.

10. Gaston Johansson F, Measurement of Pain: The psychometric properties of the Pain- 
African Journal of Reproductive Health

O-Meter, a simple inexpensive pain assessment tool that could change health care practices. J Pain symptom manage; 1996; 12: $172-81$.

11. Niven C, Murphy-Black T. Memory for labour pain: A review of the literature. Birth 2000; 27: 4, 244-55.

12. Murray A, Holdcroft A. Incidence and intensity of postpartum lower abdominal pain. BMJ 1989; l: 298.

13. Ministério de Saúde. Coordenacão do Atendimento Obstétrico de Luanda. Estatística annual de Saúde Materna Institucional 2003. CAOL, Luanda, 2004.

14. Tsu VD, Sutanto A, Vaidya K, Coffey P. Widjaya A. Oxytocin in prefilled Uniject ${ }^{\mathrm{TM}}$ injection devices for managing third-stage labor in Indonesia. International Journal of Gynecology and Obstetrics 2003; 83:103-11.

15. Strand R, Da Silva F, Jangsten E, Bergström S. A new disposable device for oxytocin administration in active management of the third stage of labour: a prospective comparative study in Angola. Acta Obstetricia et Gynecologica Scandinavica, in press.

16. Downe-Wamboldt B. Content analysis: Method, applications, and issues. Health care for Women international 1992; 13:313-21.

17. Campell M J Machin D. Medical Statistics. A Commonsense Approach.2nd ed. Oxford John Wiley \& Sons Ltd., 1993: 143.

18. Holdcroft A, Snidvongs S, Cason A, Doré C J, Berkley $\mathrm{K} J$. Pain and uterine contractions during breastfeeding in the immediate postpartum period increase with parity. Pain 2003; 104: 589-96.

19. Turner Norvell K, Gaston-Johansson F, Fridh G. Remembrance of labour pain. How valid are retrospective pain measurements? Elsevier Science Publishers B.V 1987; 31:77.

20. Weisenberg M, Caspi Z Cultural and Educational Influences on pain of childbirth. J Pain Sympt Man 1989; 41: 13-19.

21. Rofé Y, Algom D Accuracy of remembering post delivery pain. Perceptual and Motor skills 1985; 60: 99-5.

22. Fitzpatrick R Surveys of patient's satisfaction: Important general considerations. BMJ 1991; 302: 887-89.

23. Bernardt M H, Wiadnyana I G P, Wihardjo $\mathrm{H}$, Pohan I. Patient satisfaction in developing countries Soc. Sci. Med. 1999; 48: 989-96.

24. Maimbolwa C, Ransjö-Arvidson A-B, Ngándu N, Sikazwe N, Diwan V. Routine care of women experiencing normal deliveries in Zambian maternity wards: a pilot study. Midwifery 1997; 13: 125-31.

25. Amooti-Kaguna B, Nuwaha F. Factor's influencing choice of delivery sites in Rakai district of Uganda. Soc Sci Med. 2000; 50: 203-13.

26. Berg M, Lundgren I, Hermansson E, Wahlberg V. Women's experience of the encounter with the midwife during childbirth. Midwifery 1996; 12: 11-15.

27. Hunter LP. Being with woman: A guiding concept for the care of labouring women. JOGNN 2002; 31:6, 555-62. 